\title{
LIVER GLYCOGEN IN DIABETES MELLITUS
}

\author{
BY \\ J. VALLANCE-OWEN \\ From The London Hospital
}

(RECEIVED FOR PUBLICATION JULY 20, 1951)

The present consensus of opinion regarding the amount of liver glycogen in diabetes mellitus is well exemplified by Korenberg (1943), "Although opinions differ as to the exact mechanism responsible for the syndrome of diabetes mellitus, unanimity exists with regard to the fact that in that condition the hepatic glycogen is decreased ..." and Mirsky (1942), "The most important cause of diabetic ketosis and hence of the subsequent acidosis and coma is the impoverishment of the liver with respect to glycogen."

These statements are based largely on experimental work with depancreatized animals following the discovery of von Mering and Minkowski (1890) that extirpation of the pancreas in dogs resulted in permanent diabetes mellitus corresponding to the most severe form of the disease in man. These workers found only traces of glycogen in the livers of these animals and this observation has been confirmed repeatedly (Cruickshank, 1913 ; Banting, Best, Collip, Macleod, and Noble, 1922 ; Hédon, 1925 ; Fisher and Lackey, 1925 ; Major and Mann, 1932 ; and Bodo, Co Tui, and Farber, 1933).

More recently, experiments with alloxan-diabetic animals have agreed closely with the above finding. Although the liver-glycogen stores may be normal in the less severe forms of alloxan diabetes, the amount appears invariably to be reduced to minute quantities when ketosis and coma supervene, as in depancreatized animals (Goldner and Gomori, 1943 ; Hard and Carr, 1944 ; Kaplan, Franks, and Friedgood, 1945 ; Weber, 1946 ; Tuerkischer and Wertheimer, 1946 and 1947). The variability observed is possibly due to the continued production of insulin in the less severe forms, as the $\beta$-cells of the islet tissue in these animals may not have been completely necrosed.

My interest in this subject was aroused by a young diabetic, aged 21, who died in severe ketosis and coma one and a half hours after an injection of 80 units of soluble insulin. Here the glycogen content of the liver, as demonstrated histologically by Best's carmine after fixation in Bouin's fluid seven hours after death, was extremely high, the picture resembling that seen in von Gierke's disease. It seems unlikely that the deposition of glycogen could have occurred solely from the action of exogenous insulin in the time available and more probable that normal quantities of glycogen were present before the injection was given. But before making further observations on the glycogen content of the liver in human necropsy material it was obviously necessary to re-assess the rapidity with which glycogen disappears from the liver cells after death, and thus the value in general of such material. 
Although glycogen is believed to disappear rapidly from the tissues after death, Küız (1880-1) was able to esumate considerable quantities of glycogen in samples of unfixed livers of various animals after keeping the tissues at room temperature for as long as eight days. It appears from this early observation and from later work (Garnier and Lambert, 1897; Bobbitt and Deuel, 1940; Swensson, 1945) that, although glycogen does disappear from the tissues after death, the disappearance is far slower than is generally supposed. Moreover, special fixation of the tissues in alcohol or Bouin's fluid is not essential for the demonstration of glycogen.

In a preliminary investigation using rabbits' livers (Vallance-Owen, 1948) it was shown that formaldehyde is as efficient as either of the two fixatives mentioned ; also there is no appreciable loss of stainable glycogen, either during storage of liver tissue at a temperature of about $3^{\circ} \mathrm{C}$. for periods up to 48 hours, or by the subsequent processing of the tissue in the same manner as for human necropsy material. Therefore, even if quantitative estimations were to show some initial loss of glycogen within the first few minutes after death, it is permissible to use formalinfixed necropsy material for the histological demonstration of glycogen and to compare different series of cases in parallel. Moreover, the histological approach is strengthened by the findings of Popper and Wozasek (1931), who showed that there is a close similarity between the amounts so demonstrated and the actual quantities found on biochemical estimation.

\section{Present Investigation}

The series examined comprised 31 patients with diabetes mellitus dying in diabetic coma and 25 controls. Sections of the livers, formalin-fixed and paraffin-blocked, from the diabetic and control series, of an average thickness of 6-7 $\mu$, were floated on $70 \%$ alcohol at $55-60^{\circ} \mathrm{C}$., mounted and dried, and after the paraffin had been removed were covered with a film of $1 \%$ celloidin. They were then stained with haematoxylin and Best's carmine (Carleton and Leach, 1938). Control sections in each case were treated with saliva before staining.

On microscopic examination the sections were graded in respect of the amount of glycogen present in the cytoplasm of the liver cells, according to the following scheme : + indicated several lobules devoid of glycogen, elsewhere granules scattered diffusely through the liver lobule or in well-circumscribed areas; ++ small glycogen particles scattered throughout almost the whole of each lobule with or without increased deposition in certain areas $;+++$ glycogen particles larger and slightly more numerous than in $++;++++$ glycogen particles further increased in number and size; +++++ glycogen in large quantities throughout the liver parenchyma. This is only to give an idea of how the quantity of glycogen was assessed, the individual variation in the distribution being recorded separately.

Diabetic Series.-The cases were divided into those which had not received insulin, 15 cases, of which 12 dated to the years before insulin was introduced, and those which had received insulin, 16 cases. All these patients had gross glycosuria and ketonuria and died in coma (see Appendix).

Control Series.-This consists of 25 cases dying of conditions other than diabetes mellitus, in which carbohydrate metabolism was not involved and where the liver was not diseased. Thirteen of these cases were chronic hospital patients whose death occurred from debilitating diseases. The remaining 12 patients died rapidly from acute medical conditions or as a result of accidents. The latter are obviously preferable as "normal" controls, but the former group is included, since Popper and 
Wozasek (1931) argued that it was more reasonable to compare the livers of diabetics with those of patients dying from some other cachectic state.

Both in the diabetic and control series all the livers in which glycogen could be demonstrated were found to be devoid of it following treatment with saliva.

\section{Results}

From Table I it can be seen that the livers in the control series where death was due to a debilitating disease had an uneven content of glycogen. In general it was

TABLE I

Results of ANalyses for Glycogen in Diabetic and Control livers

\begin{tabular}{|c|c|c|c|c|c|c|c|}
\hline \multicolumn{4}{|c|}{ Diabetic Series } & \multicolumn{4}{|c|}{ Control Series } \\
\hline $\begin{array}{l}\text { Case } \\
\text { No. }\end{array}$ & No Insulin & $\begin{array}{l}\text { Case } \\
\text { No. }\end{array}$ & Insulin & $\begin{array}{l}\text { Case } \\
\text { No. }\end{array}$ & $\begin{array}{c}\text { Debilitating } \\
\text { Conditions }\end{array}$ & $\begin{array}{l}\text { Case } \\
\text { No. }\end{array}$ & $\begin{array}{l}\text { Sudden Death } \\
\text { ("Normal ") }\end{array}$ \\
\hline $\begin{array}{r}1 \\
2 \\
3 \\
4 \\
5 \\
6 \\
7 \\
8 \\
8 \\
9 \\
10 \\
11 \\
12 \\
13 \\
14 \\
15\end{array}$ & $\begin{array}{c}\text { Nil } \\
+++ \\
++ \\
++ \\
++ \\
\text { Nil } \\
+++ \\
\quad \text { Nil } \\
+\quad \\
++++ \\
++ \\
\quad \text { Nil } \\
++++ \\
\quad \text { Nil } \\
+++ \\
+++\end{array}$ & $\begin{array}{l}16 \\
17 \\
18 \\
19 \\
20 \\
21 \\
22 \\
23 \\
24 \\
25 \\
26 \\
27 \\
28 \\
29 \\
30 \\
31\end{array}$ & $\begin{array}{l}+++ \\
++ \\
++++ \\
\quad \text { Nil } \\
\quad \text { Nil } \\
++ \\
++ \\
\quad \text { Nil } \\
++ \\
+++ \\
+++ \\
+++++ \\
++++ \\
++++ \\
+++ \\
+++++\end{array}$ & $\begin{array}{r}1 \\
2 \\
3 \\
4 \\
5 \\
6 \\
7 \\
8 \\
9 \\
10 \\
11 \\
12 \\
13\end{array}$ & $\begin{array}{l}\text { Nil } \\
\text { Nil } \\
++ \\
\text { Nil } \\
+ \\
+ \\
\text { Nil } \\
+ \\
++ \\
+ \\
+ \\
\text { Nil } \\
+ \\
\text { Nil } \\
\text { Nil }\end{array}$ & $\begin{array}{l}14 \\
15 \\
16 \\
17 \\
18 \\
19 \\
20 \\
21 \\
22 \\
23 \\
24 \\
25\end{array}$ & $\begin{array}{l}++ \\
++ \\
+++ \\
+++ \\
++ \\
+ \\
++ \\
++ \\
++ \\
++ \\
+++ \\
+++ \\
+++\end{array}$ \\
\hline
\end{tabular}

small and frequently it was absent. In the patients dying rapidly from acute medical conditions or as a result of accidents the livers were reasonably uniform and contained much more glycogen ; these have been taken as normal controls. Although six of the 15 livers of patients dying in diabetic ketosis and coma without insulin showed little or no glycogen, the remaining nine showed as much or more than the normal controls and considerably more than in those of patients dying from debilitating diseases. The diabetics dying in coma, having received insulin, showed a uniformly increased deposition of glycogen in the liver over the controls if the cases before 1931 are excluded (Cases 16-24). Where glycogen was present, it was most marked in the cells of the periportal region, much less, and frequently none, being demonstrated round the central vein, although present elsewhere throughout the lobule. There appeared to be no antagonism between the deposition of glycogen and fat; both were often present in large amounts.

\section{Discussion}

These findings agree well with the early observations of Külz (1880-1), Geelmuyden (1920), Warren (1930), and Popper and Wozasek (1931). All these workers found normal or increased amounts of liver glycogen in many of their patients dying in diabetic coma, although they had received no insulin. 
Recently Hildes, Sherlock, and Walshe (1949) applied the aspiration biopsy technique for obtaining specimens of liver to unanaesthetized diabetic patients. They were unable to obtain a statistically significant difference between the values for liver glycogen in their diabetic and control series. But though insulin was discontinued at least two days before the biopsies were taken, the majority of the cases were only mildly ketotic. Using the same technique, Bondy, Sheldon, and Evans (1949) found reduced quantities of glycogen in the majority of their cases with diabetic ketosis, but they had one patient in semicoma from that condition in whom greatly increased quantities were found. The results are at variance with those in experimental depancreatized and alloxan-diabetic animals where hepatic glycogen deposits are uniformly reduced to minimal traces when ketosis occurs.

Turning to the cases of the present series which had been treated with insulin, the results from 1931 onwards (Cases 25-31) have been remarkably uniform and show an increased deposition of glycogen. This date coincides with the advent of pure crystalline insulin. Previously, impure, non-crystalline insulin was used and this apparently contains varying amounts of a glycogenolytic factor, as has been pointed out by Bouckaert and de Duve (1947), and has been responsible for the early conflicting reports on the effect of the hormone. The erratic results from 1925 to 1931 in the insulin-treated group can possibly be explained on these grounds. Otherwise the findings here confirm those of the above authors, who are satisfied that, provided the blood sugar is maintained at normal or elevated levels, then hepatic glycogen will regularly be found to increase under the action of pure insulin. They go on to stress that the normal regulator of sugar metabolism is the blood sugar itself and that the effect of insulin depends on it. Also Soskin (1930) showed that every criterion of carbohydrate utilization can be obtained without insulin in the depancreatized animal. Moreover, Mirsky and his colleagues (Mirsky, Heiman, and Broh-Kahn, 1937a, and Mirsky, Heiman, and Swadesh, 1937b) have shown that the antiketogenic and nitrogen-sparing effects of carbohydrate can be obtained in depancreatized dogs, provided the blood sugar is raised to sufficiently high levels. Major and Mann (1932) and Bodo et al. (1933) found deposition of glycogen in the livers of their depancreatized animals when given glucose intravenously, although at a rate far below that in the normal animal. Thus it would appear that insulin acts as a catalyst in carbohydrate metabolism, allowing the tissues to achieve at normal or low blood sugar levels that for which high levels are required in its absence.

From the results of other investigators and those presented in this paper, it is clear that cases of human diabetes mellitus in severe ketosis can be divided into two broad groups, those with little or no glycogen in the liver and those with normal or increased amounts of that substance. In view of what has already been stated regarding insulin action and the fact that depancreatized animals invariably show very low levels of hepatic glycogen, the difference in the two groups may be explained on a basis of circulating insulin. Those cases with negligible quantities of glycogen had little or no insulin circulating and the blood sugar had not risen to sufficiently high levels to promote any storage, whereas those with normal or increased amounts of glycogen presumably had appreciable quantities of circulating hormone, perhaps in normal or even increased amounts in some cases, or alternatively had excessively high blood sugar levels. That such high blood sugar 
levels alone could cause the elevation of hepatic glycogen storage to even normal amounts has been dismissed as improbable in view of the work of Bodo et al. (1933).

As ketosis and coma can occur in diabetes mellitus with normal or increased amounts of glycogen in the liver, the present conception of its aetiology must be revised at least in relation to this disease. For many years the fundamental abnormality in diabetes mellitus was thought to be the non-utilization of sugar. There is now considerable evidence to indicate that the diabetic organism, maintaining a high blood sugar level, is using as much and often more sugar than the normal organism at its usual blood sugar level (Mann and Magath, 1923; Macleod and Markowitz, 1926; Soskin, 1930 ; Soskin and Levine, 1937; Zilversmit, Chaikoff, Feller, and Masoro, 1948). In the light of this work an alternative theory of the mechanism of the diabetic state has been put forward, ascribing the hyperglycaemia and glycosuria to an over-production of glucose from protein and fat, probably in the liver. This excessive production is sufficient to cause accumulation and excretion of excess sugar in spite of the continued oxidation of glucose at the normal rate. Fats break down into glycerol and fatty acid, glycerol is built up to glucose via phosphoglyceraldehyde, and the fatty acids are converted into acetoacetic acid by way of acetic acid. There is still much doubt as to whether fatty acids can be converted into glucose. But Weil-Malherbe (1938) has demonstrated, in kidney slices from the rat, the in vitro formation of sugar from added aceto-acetic acid.

On the basis of the over-production theory of diabetes mellitus the appearance of ketosis in this condition with glycogen-loaded livers can be explained. As the breakdown of fat proceeds, aceto-acetic acid is formed at a rate greater than that of its utilization and possible conversion to sugar, and so ketosis develops. There is no indication that the peripheral tissues of the diabetic organism dispose of ketones any less rapidly than those of the normal animal (Chaikoff and Soskin, 1928). The antiketogenic properties of glucose and insulin in diabetes mellitus would therefore appear to depend on the inhibition of gluconeo-genesis from fat, the former indirectly by raising the blood sugar level artificially (Mirsky et al., 1937a) and the latter directly, and not, as was previously believed, by restoration of liver glycogen.

Excessive gluconeo-genesis would certainly appear to be the mechanism of the production of the diabetic state associated with acromegaly, Cushing's basophilism, and certain tumours of the adrenal cortex (Sprague, Priestley, and Dockerty, 1943). In view of this theory it would seem reasonable to suppose that many cases of diabetes mellitus arise from over-action of the pituitary gland, either directly or through the adrenal. There is, however, no factual evidence to support it, but the overall evidence upon which the pancreas is incriminated is slight. It is well known that, at necropsy, this gland gives no constant indication of the severity of the condition and is frequently normal macroscopically and microscopically (e.g. Warren and Root, 1925 ; Wright, 1927 ; White, 1939 ; Susman, 1942).

It is interesting to note the relationship of islet change to hyperglycaemia studied by Lukens, Dohan, and Wolcott (1943). These workers showed that neither partial pancreatectomy nor injections of anterior pituitary extract would cause hydropic degeneration in the $\beta$-cells of the islets in the absence of hyperglycaemia, but both procedures caused it after hyperglycaemia had been present for two to three weeks. 
They go on to point out that hyperglycaemia caused by continuous perfusion of glucose can result in minor changes in the islet tissue. From these experiments and observations it seems possible that any physiological or morbid anatomical changes in the pancreas, found occasionally in diabetes mellitus, are merely secondary to the hyperglycaemia produced by excessive gluconeo-genesis through some agent, possibly the pituitary gland, as yet unknown. As might be expected, any changes found seem to be confined to the older patients, in whom the islet tissue is ageing and vascular factors come into play.

Finally, completely depancreatized human beings can be kept quite stable on small quantities of insulin, such as 20 units twice a day, as was shown by Goldner and Clarke (1944), and now the phenomenon is seen frequently in patients who have undergone pancreatectomy for carcinoma of the pancreas. This is a strong argument for believing that the picture in depancreatized and alloxan-diabetic animals is not truly comparable with diabetes mellitus as seen in man, and readily explains the differences in the literature which have occurred when comparing these two groups, particularly with reference to liver glycogen. It must now be believed that in many cases of diabetes mellitus normal quantities of insulin are circulating and that the condition is due, not to some pathological condition of the pancreas, but rather to some other cause or causes which have not yet been firmly established.

\section{Summary}

The liver glycogen has been studied histologically in 31 patients with diabetes mellitus dying in coma and compared with controls.

It has been shown that diabetic ketosis and coma can occur with normal or increased glycogen deposits in the liver. Such normal or increased glycogen deposits are frequently found in untreated human diabetes mellitus. Pure insulin causes an increase in glycogen deposition in the liver.

The bearing of these findings upon present conceptions of diabetes mellitus is discussed.

I should like to thank Professor Dorothy Russell for her invaluable encouragement and criticism, and Professor J. R. Marrack for assistance with the biochemistry.

At one stage during the completion of this work I was in receipt of a grant from the Freedom Research Fund of The London Hospital, for which I am much indebted.

\section{BIBLIOGRAPHY}

Banting, F. G., Best, C. H., Collip, J. B., Macleod, J. J. R., and Noble, E. C. (1922). Trans. roy. Soc. Can., 16, Sect. V, 39.

Bobbitt, B. G., and Deuel, H. J. (1940). Amer. J. Physiol., 131, 521.

Bodo, R. C., Co Tui, F., and Farber, L. (1933). Ibid., 103, 18.

Bondy, P. K., Sheldon, W. H., and Evans, L. D. (1949). J. clin. Invest., 28, 1216.

Bouckaert, J.'P., and de Duve, C. (1947). Physiol. Rev., 27, 39.

Carleton, H. M., and Leach, E. H. (1938). Histological Technique, 2nd ed., pp. 106 and 171. London.

Chaikoff, I. L., and Soskin, S. (1928). Amer. J. Physiol., 87, 58.

Cruickshank, E. W. H. (1913). J. Physiol., Lond., 47, 1.

Fisher, N. F., and Lackey, R. W. (1925). Amer. J. Physiol., 72, 43.

Garnier, L., and Lambert, M. (1897). C. R. Soc. Biol., Paris, $10 \mathrm{ser}, 4,718$.

Geelmuyden, H. C. (1920). Acta med. scand., 53, 381.

Goldner, M. G., and Clark, D. E. (1944). J. clin. Endocrinol., 4, 194. and Gomori, G. (1943). Endocrinology, 33, 297.

Hard, W. L., and Carr, C. J. (1944). Proc. Soc. exp. Biol., N.Y., 55, 214.

Hédon, E. (1925). C. R. Soc. Biol., Paris, 93, 596. 
Hildes, J. A., Sherlock, S., and Walshe, V. (1949). Clin. Sci., 7, 287.

Kaplan, N. O., Franks, M., and Friedgood, C. E. (1945). Science, 102, 447.

Korenberg, M. (1943). Arch. intern. Med., 72, 746.

Külz, E. (1880-1). Pflüз. Arch. ges. Physiol., 24, pp. 1-114.

Lukens, F. D. W., Dohan, F. C., and Wolcott, M. W. (1943). Endocrinology, 32, 475.

Macleod, J. J. R., and Markowitz, J. (1926). Trans. Ass. Amer. Phys., 41, 147.

Major, S. G., and Mann, F. C. (1932). Amer. J. Physiol., 102, 409.

Mann, F. C., and Magath, T. B. (1923). Arch. intern. Med., 31, 797.

Mering, J. von, and Minkowski, O. (1890). Arch. exp. Path. Pharmak., 26, 371.

Mirsky, I. A. (1942). J. Amer. med. Ass., 118, 690.

- Heiman, J. D., and Broh-Kahn, R. H. (1937a). Amer. J. Physiol., 118, 290.

- and Swadesh, S. (1937b). Ibid., 120, 681 .

Popper, H., and Wozasek, O. (1931). Virchows Arch., 279, 819.

Soskin, S. (1930). J. Nutrit., $3,99$.

- and Levine, R. (1937). Amer. J. Physiol., 120, 761.

Sprague, R. G., Priestley, J. T., and Dockerty, M. B. (1943). J. clin. Endocrinol., 3, 28.

Susman, W. (1942). Ibid., $2,97$.

Swensson, A. (1945). Acta physiol. scand., Suppl. 33, p. 47.

Tuerkischer, E., and Wertheimer, E. (1946). Nature, Lond., 158, 201.

- (1947). J. Endocrinol., 5, 229.

Vallance-Owen, J. (1948). J. Path. Bact., 60, 325.

Warren, S. (1930). Amer. J. med. Sci., 179, 482.

and Root, H. F. (1925). Amer. J. Path., 1, 415.

Weber, H. (1946). Nature, Lond., 158, 627.

Weil-Malherbe, H. (1938). Biochem. J., 32, 2276.

White, P. (1939). Arch. intern. Med., 63, 39.

Wright, A. W. (1927). Amer. J. Path., 3, 461.

Zilversmit, D. B., Chaikoff, I. V., Feller, D. D., and Masoro, E. J. (1948). J. biol. Chem., 176, 389.

\section{L I N I C A L A P P E N D I X}

\section{Diabetic Series}

The following cases did not receive insulin.

Case 1.-Male, 65 years. Carbuncle of neck precipitated the coma; duration not known.

P.M., 232/11, 48 hours after death. Body weight $140 \mathrm{lb}$. Liver (3 lb. $14 \mathrm{oz}$.) congested and fatty. Microscopically moderate fatty infiltration. Glycogen absent.

Case 2.-Female, 24 years. Diabetes for five years, on diet. Coma five days after admission and died after further two days.

P.M., 675/12, less than 24 hours after death. Body weight $75 \mathrm{lb}$. Liver (?) oedematous and engorged, with, microscopically, moderate fatty infiltration. Glycogen +++ , diffuse with accentu- ation round portal systems and central veins.

Case 3.-Male, 14 years. Ill for 14 days with cold ; developed wasting, great thirst and polyuria; one day into coma; died four and a half hours after admission.

P.M., 134/15, less than 24 hours after death. Body weight $58 \mathrm{lb}$. Liver $(1 \mathrm{lb} .14$ oz.) showed fatty degeneration with few submiliary granulomatous tubercles in capsule, and microscopically gross fatty degeneration. Glycogen ++ , prominent round portal veins and midzones, absent round central veins.

Case 4.-Male, 55 years. One year diabetic symptoms, on diet. Two weeks influenza. Three days in coma and two days before death blood sugar $0.6 \%$.

P.M., 632/20, 24 hours after death. Body weight $87 \mathrm{lb}$. Liver (2 lb. $8 \mathrm{oz}$.) showed brown atrophy and microscopic- 
ally slight to moderate fatty degeneration. Glycogen + +, prominent round portal systems extending to midzones, absent round central veins.

Case 5.-Female, 35 years. Six months symptoms of diabetes mellitus. In coma one day before admission, died in 12 hours.

P.M., $190 / 21,30$ hours after death. Body weight $95 \mathrm{lb}$. Liver $(3 \mathrm{lb}$. $4 \mathrm{oz}$.) showed oedema and cloudy swelling. Microscopically fatty degeneration slight. Glycogen almost absent, but traces around portal systems.

Case 6.-Male, 36 years. Six months diabetic symptoms. In coma two days, blood sugar $0.44 \%$ one day before death.

P.M., 578/21, 24 hours after death. Body weight $89 \mathrm{lb}$. Liver (3 lb. $10 \mathrm{oz}$.) congested with fatty degeneration. Microscopically fatty degeneration moderate to severe. Glycogen +++ , small quantities scattered throughout the lobules but main component in well circumscribed areas in varying parts of the liver lobule.

Case 7.-Male, 21 years. Seven days "acute diabetes mellitus," died in coma three days after admission.

P.M., 232/22, 106 hours after death. Body weight $106 \mathrm{lb}$. Liver (3 lb. $5 \mathrm{oz}$.) showed congestion and moderate parenchymatous degeneration with scattered pinhead focal necrosis. Microscopically fatty change slight. Glycogen was absent.

Case 8.-Female, 38 years. Into coma one day, admitted and died in 12 hours.

P.M., 315/22, 30 hours after death. Body weight $99 \mathrm{lb}$. Liver (5 lb. $12 \mathrm{oz}$.) showed parenchymatous degeneration. Microscopically fatty degeneration slight. Glycogen +, periportal distribution.

Case 9.-Female, 46 years. Five years increasing thirst and appetite with developing acromegaly. Admitted in coma and died in two days.

P.M., 435/22, 20 hours after death. Body weight $145 \mathrm{lb}$. Liver $(7 \mathrm{lb}$. $3 \mathrm{oz}$.) enlarged and flabby with scattered areas of focal necrosis. Microscopically fatty degeneration moderate. Glycogen ++++ , diffuse with slight accentuation round portal systems.
Case 10.-Female, 70 years. Gangrene left foot precipitated ketosis. Blood sugar one week before death $0.23 \%$, in coma two days.

P.M., 468/22, 24 hours after death. Body weight $143 \mathrm{lb}$. Liver (3 lb. $12 \mathrm{oz}$.) showed fine reticular fibrosis. Microscopically fatty degeneration slight, fibrosis marked. Glycogen ++ , scattered diffusely through the lobule with slight accentuation round portal systems.

Case 11.-Female, 67 years. Three years diabetes mellitus, gangrene right foot precipitated coma. Blood sugar three days before death $0.3 \%$.

P.M., 480/22, 20 hours after death. Body weight $157 \mathrm{lb}$. Liver ( $3 \mathrm{lb} .13 \mathrm{oz}$.) showed fatty degeneration, and microscopically marked fatty degeneration. Glycogen was absent.

Case 12.-Female, 50 years. Ten days unwell with headache. Seven days discharging right ear with increasing appetite, polyuria, and polydipsia. Four days, semicoma, fluctuating in depth. One day, deep coma.

P.M., 519/22, 28 hours after death. Body weight $176 \mathrm{lb}$. Liver (4 lb. $6 \mathrm{oz}$.) large and flabby with fatty degeneration. Microscopically moderate fatty degeneration. Glycogen ++++ , diffuse with no particular accentuation.

Case 13.-Female, 73 years. Diabetes mellitus for many years, on 30 units b.d. Admitted in coma and died quickly. No insulin given.

P.M., 198/33, 12 hours after death. Body weight $327 \mathrm{lb}$. Liver (3 lb. $12 \mathrm{oz}$.) showed central congestion and atrophy. Microscopically fatty degeneration moderate. Glycogen was absent.

Case 14.-Female, 74 years. Seventeen years diabetes mellitus, no insulin. Admitted in semicoma, blood sugar $0.29 \%$. Passed into deep coma and no insulin given.

P.M., 403/34, six hours after death. Body weight $173 \mathrm{lb}$. Liver ( $3 \mathrm{lb}$.) oedematous. Microscopically fatty degeneration moderate. Glycogen +++ , diffuse with accentuation round portal systems. 
Case 15.-Female, 67 years. Fourteen years diabetes mellitus, on soluble insulin $20: 40$. One day, drowsy with occasional epileptic fits. Blood sugar $0.24 \%$ on admission. Fits controlled by potassium bromide and chloral, but given no insulin. Gradually into deepening coma and died two days later.

P.M., 394/38, four hours after death. Body weight $87 \mathrm{lb}$. Liver $(2 \mathrm{lb} .9 \mathrm{oz}$.) showed diffuse congestion. Microscopically fatty degeneration moderate. Glycogen +++ , diffuse with slight accentuation round portal systems.

The following cases received insulin.

Case 16.-Male, 21 years. Three weeks symptoms of diabetes mellitus, admitted in semicoma. Insulin 40 units three-hourly and blood sugar down to $0.12 \%$. Last insulin injection 14 hours before death, and three hours before death blood sugar $0.5 \%$.

P.M., 83/25, 40 hours after death. Body weight $105 \mathrm{lb}$. Liver ( $3 \mathrm{lb} .4 \mathrm{oz}$.) showed oedema, congestion, and fatty degeneration. Microscopically fatty degeneration moderate. Glycogen +++ , diffuse with slight accentuation round portal systems.

Case 17.-Female, 42 years. Four years diabetes mellitus, admitted in coma, given 60 units insulin, died " in a few hours."

P.M., 88/27, 36 hours after death. Body weight $86 \mathrm{lb}$. Liver (2 lb. $11 \mathrm{oz}$.) showed focal necrosis. Microscopically fatty degeneration slight. Glycogen ++ , diffuse with slight accentuation round portal systems.

Case 18.-Female, 47 years. No previous diabetic history, admitted in semicoma. Blood sugar not recorded. Given 30 units soluble insulin on admission and thereafter 20 units two-hourly for 48 hours, i.e., 510 units in all, but died in coma 72 hours after admission.

P.M., 96/27, 22 hours after death. Body weight $131 \mathrm{lb}$. Liver $(3 \mathrm{lb} .3 \mathrm{oz}$.) showed oedema and parenchymatous degeneration. Microscopically fatty degeneration moderate. Glycogen ++++ , diffuse.
Case 19.-Female, 16 years. Three years diabetic, admitted in coma. Blood sugar $0.44 \%$. Given 95 units insulin at once but no effect, died five hours after admission.

P.M., 392/27, 28 hours after death. Body weight $118 \mathrm{lb}$. Liver (3 lb. $7 \mathrm{oz}$.) showed oedema and severe parenchymatous degeneration. Microscopically fatty degeneration slight. No glycogen.

Case 20.-Female, 30 years. One year diabetes mellitus, on diet and 25 units insulin b.d. Admitted in coma, blood sugar $0.4 \%$, insulin 50 units hourly for six hours. Blood sugar then $0.33 \%$, died in coma seven hours after admission.

P.M., 572/27, 11 hours after death. Body weight $93 \mathrm{lb}$. Liver (3 lb. $4 \mathrm{oz}$.) showed oedema, congestion, and parenchymatous degeneration. Microscopically fatty degeneration moderate. No glycogen.

Case 21.-Female, 64 years. Three days before became "ill and weak." Admitted in coma, blood sugar $0.4 \%$, given 50 units insulin hourly for seven hours, last injection three hours before death. One hour before death blood sugar $0.42 \%$.

P.M., 14/28, nine hours after death. Body weight $85 \mathrm{lb}$. Liver $(2 \mathrm{lb} .12 \mathrm{oz}$.) showed oedema and central congestion. Microscopically fatty degeneration very slight. Glycogen ++ , irregular with greatest accumulation round portal systems.

Case 22.-Female, 46 years. One week carbuncle of neck, two weeks frequency and thirst. Admitted in coma. Blood sugar $0.4 \%$. Given insulin 30 units hourly for three hours, no effect. Died four hours after admission.

P.M., 325/28, 20 hours after death. Body weight $99 \mathrm{lb}$. Liver (3 lb. $11 \mathrm{oz}$.) showed post-mortem degeneration. Microscopically fatty degeneration, slight to moderate. Glycogen ++ , diffuse.

Case 23.-Female, 19 years. Four days ill, weak and drowsy. Admitted in coma, blood sugar $0.65 \%$. Given 50 units insulin intravenously, died in one and a half hours. 
P.M., 416/29, 39 hours after death. Body weight $91 \mathrm{lb}$. Liver ( $2 \mathrm{lb} .7 \mathrm{oz}$. showed oedema, congestion, and parenchymatous degeneration. Microscopically fatty change moderate. No glycogen.

Case 24.-Male, 19 years. Sore throat and thirst, admitted in coma. Blood sugar $1.0 \%$, given 100 units insulin at once and 50 units one hour later. Died three hours after admission.

P.M., 298/30, 40 hours after death. Body weight $94 \mathrm{lb}$. Liver (2 lb. $14 \mathrm{oz}$.) showed severe parenchymatous degeneration. Microscopically fatty degeneration severe. Glycogen ++ , diffuse.

Case 25.-Male, 30 years. Diabetic on 10 units insulin b.d. Had diabetic cataract. Admitted in coma. Blood sugar $0.8 \%$. Insulin 50 units. Died threequarters of an hour after admission.

P.M., 96/31, 12 hours after death. Body weight $166 \mathrm{lb}$. Liver $(3 \mathrm{lb} .9 \mathrm{oz}$.) showed oedema, congestion, and focal degeneration. Microscopically fatty change severe. Glycogen +++ , diffuse but irregular with accentuation round portal systems.

Case 26.-Female, 25 years. One year diabetes mellitus, on diet, and 40 units t.d.s. Admitted in coma. Blood sugar $0.28 \%$. Given 30 units insulin at once and four hours later 40 units. Died eight hours after admission.

P.M., 151/31, 13 hours after death. Body weight $120 \mathrm{lb}$. Liver (5 lb.) showed severe parenchymatous degeneration. Microscopically fatty degeneration severe. Glycogen +++ , diffuse.

Case 27.-Female, 55 years. One and a half years diabetic symptoms, on diet and insulin 22 units b.d. Insulin stopped for ? three days. Admitted in coma, with blood sugar $0.8 \%$. Insulin 60 units at once, two hours later 100 units and after further two hours 100 units. Blood sugar one hour after last injection $0.9 \%$. Patient died about half an hour after this.

P.M., 236/31, 14 hours after death. Body weight $80 \mathrm{lb}$. Liver (3 lb. $4 \mathrm{oz}$.) showed parenchymatous degeneration.
Microscopically fatty degeneration moderate. Glycogen +++++ , diffuse.

Case 28.-Male, 69 years. Five years diabetic, admitted in coma with blood sugar $0.7 \%$. Insulin 60 units one and a half hours before admission, then 20 units hourly for four hours followed by 40 units hourly for four hours. No response. Blood sugar $1.0 \%$ half an hour before death.

P.M., 350/34, 27 hours after death. Body weight $129 \mathrm{lb}$. Liver $(3 \mathrm{lb}$. $6 \mathrm{oz}$.) was parenchymatous and showed fatty degeneration. Microscopically fatty degeneration severe. Glycogen ++++ , diffuse with accentuation round portal systems.

Case 29.-Female, 25 years. No previous diabetic history, admitted in coma, blood sugar $0.5 \%$. Insulin 100 units at once, followed by 400 units over next six hours. No effect, died seven hours after admission.

P.M., 219/35, nine hours after death. Body weight $82 \mathrm{lb}$. Liver (3 lb. $2 \mathrm{oz}$.) showed parenchymatous degeneration. Microscopically fatty degeneration moderate. Glycogen ++++ , periportal and midzonal, almost absent round central veins.

Case 30.-Female, 21 years. Known diabetic, admitted in coma when blood sugar $0.52 \%$. Insulin 40 units two-hourly for six hours (120 units in all). No effect, died seven hours after admission.

P.M., $87 / 45,24$ hours after death. Body weight $100 \mathrm{lb}$. Liver $(5 \mathrm{lb} .11 \mathrm{oz}$.) showed slight central congestion. Microscopically fatty degeneration severe. Glycogen +++ , diffuse. Liver fixed in Bouin's fluid.

Case 31.-Male, 21 years. Known diabetic, admitted in coma. Blood sugar $0.5 \%$. Insulin 80 units intravenously. No effect, died one and a half hours after admission.

P.M., 226/46, seven hours after death. Body weight $116 \mathrm{lb}$. Liver (7 lb. $8 \mathrm{oz}$.) showed parenchymatous degeneration. Microscopically fatty degeneration severe. Glycogen +++++ , diffuse with slight periportal accentuation. 


\section{Control Series}

The following patients died of debilitating diseases. All necropsy findings reported in this series are macroscopic except for liver glycogen.

No. 1.-Female, 21 years. Heart failure, septicaemia, acute fibrinous on chronic rheumatic carditis, pregnancy.

P.M., 434/14, 18 hours after death. Liver anaemic and oedematous. No glycogen.

No. 2.-Male, 60 years. Oedema of glottis, pernicious anaemia.

P.M., 368/15, 24 hours after death. Liver showed slight enlargement, " creamy chocolate." No glycogen.

No. 3.-Male, 49 years. Double actinomycotic emphysema. Actinomycosis of wall of left chest.

P.M., 388/15, 20 hours after death. Liver showed parenchymatous degeneration. Glycogen ++ .

No. 4.-Male, 59 years. Heart failure, subacute nephritis.

P.M., 111/26, 16 hours after death. Liver showed pinhead flecks of fibrosis in capsule, central congestion. No glycogen.

No. 5.-Female, 34 years. Serofibrinous pericarditis, slight cardiovascular hypertrophy, subacute nephritis.

P.M., 143/26, 18 hours after death. Liver showed oedema and central congestion. Glycogen + .

No. 6.-Female, 34 years. Oedema and collapse of lungs, ileus, pelvic peritonitis. Operation, caesarean section. Died six days following operation.

P.M. 174/34, 20 hours after death. Liver slightly enlarged and pale. No glycogen.

No. 7.-Female, 33 years, meningeal and cerebral haemorrhages, thrombocytopenic purpura.

P.M., 244/34, 16 hours after death. Liver showed oedema and diffuse congestion. Glycogen +.

No. 8.-Female, 22 years. Solid oedema of lungs, heart failure, Graves's disease and pregnancy (admitted in heart failure and died in three days).
P.M., 415/34, 18 hours after death. Liver showed parenchymatous degeneration. Glycogen + +.

No. 9.-Male, 41 years. Acute bronchitis, carcinoma of duodenum at ampulla of Vater. Old operation, cholecystgastrostomy.

P.M., 139/47, 30 hours after death. Liver showed parenchymatous degeneration. Glycogen +.

No. 10.-Male, 69 years. Fractured skull, purulent meningitis. Improved for six days, then died in 36 hours.

P.M., 149/47, eight hours after death. Liver showed slight fatty degeneration. No glycogen.

No. 11.-Male, 33 years. Cerebral herniation, spongioblastoma of right temporal lobe. Died nine hours after exploration.

P.M., 287/48, eight hours after death. Liver showed slight central congestion. Glycogen +.

No. 12.-Male, 59 years. Peritonitis, leaking caecostomy, carcinoma of pelvirectal junction.

P.M., 310/47, 15 hours after death. Liver showed accentuation of portal systems. No glycogen, but nuclear glycogen marked.

No. 13.-Female, 37 years. Multiple emboli, infarction of lung, mitral stenosis, and heart failure.

P.M., 55/48, 24 hours after death. Liver showed congestion. No glycogen.

The following are brief reports of patients dying quickly from acute medical conditions or as a result of accidents.

No. 14.-Male, 55 years. Acute heart failure, syphilitic aortitis with obstruction to coronaries. Brought in dead by police.

P.M., 489/14, 18 hours after death. Liver showed slight oedema with diffuse congestion. Glycogen + +.

No. 15.-Male, 62 years. Heart failure, cardiovascular hypertrophy, chronic nephritis. Admitted with heart failure and found to have cloud of albumin in urine. Reacted well to digitalis with improvement 


\section{LIVER GLYCOGEN IN DIABETES MELLITUS}

in dyspnoea and loss of oedema. Died suddenly while walking in the ward.

P.M., 373/19, 36 hours after death. Liver showed slight portal fibrosis ; diffuse congestion. Glycogen ++ .

No. 16.-Male, 47 years. Death under anaesthetic for removal of carcinoma of right tonsil, syphilitic aortitis (mild).

P.M., 589/19, 18 hours after death. Liver showed slight oedema, diffuse congestion. Glycogen +++ .

No. 17.-Female, 53 years. Cerebral haemorrhage, nephritis repens. Suddenly collapsed in the street, died soon after admission.

P.M., 269/31, 17 hours after death. Liver showed oedema. Glycogen +++ .

No. 18.-Male, 61 years. Heart failure. Organizing infarct of myocardium, thrombosis of atheromatous coronary arteries. Two and a half years angina of effort; sudden severe attack of substernal pain; died four hours later.

P.M., 172/34, seven hours after death. Liver showed oedema and slight focal congestion. Glycogen ++ .

No. 19.-Male, 56 years. Pulmonary embolus, thrombosis in iliac veins. Organizing lobar pneumonia. Nine days following crisis, when convalescent, suddenly called for bedpan and died.

P.M., 434/34, 16 hours after death. Liver showed slight congestion, pale. Glycogen +.

No 20.-Male, 47 years. Brought in dead. Acute heart failure. Slight stenosis of coronaries by atheroma. Had pain in chest for one day, suddenly collapsed.
P.M., 155/47, six hours after death. Liver showed diffuse congestion. Glycogen ++ .

No. 21.-Male, 45 years. Fracture of cervical vertebrae. Died in three hours following accident.

P.M., 158/47, 24 hours after death. Liver showed slight congestion. Glycogen ++ .

No. 22.-Male, 66 years. Acute on chronic heart failure. Old cardiac infarction. One and a half years before cardiac infarction, good recovery. Sudden chest pain with acute distress, died four hours after admission.

P.M., 289/47, seven hours after death. Liver showed central congestion. Glycogen ++ .

No. 23.-Male, ? 60 years. Brought in dead. Acute heart failure, severe stenosis of coronary arteries by atheroma.

P.M., 294/47, 22 hours after death. Liver showed severe central congestion. Glycogen +++ .

No. 24.-Male, 46 years. Cerebral haemorrhage, cardiovascular hypertrophy, hypertension. Sudden coma one and a half hours before admission, died in three hours.

P.M., 304/47, 12 hours after death. Liver normal. Glycogen +++ .

No. 25.-Ma'e, 25 years. Fractured skull, posterior dislocation of right head of femur. Died 10 hours after the accident.

P.M., 68/48, five hours after death. Liver showed oedema. Glycogen +++ .

Both in the diabetic and control series all the livers in which glycogen could be demonstrated were found to be devoid of it after treatment with saliva. 